\title{
Direct evidence for positron annihilation from shallow traps
}

\section{Linderoth, Søren; Hidalgo, C.}

\section{Published in:}

Physical Review B

Link to article, DOI:

10.1103/PhysRevB.36.4054

Publication date:

1987

\section{Document Version}

Publisher's PDF, also known as Version of record

Link back to DTU Orbit

Citation (APA):

Linderoth, S., \& Hidalgo, C. (1987). Direct evidence for positron annihilation from shallow traps. Physical Review B, 36(7), 4054-4057. https://doi.org/10.1103/PhysRevB.36.4054

\section{General rights}

Copyright and moral rights for the publications made accessible in the public portal are retained by the authors and/or other copyright owners and it is a condition of accessing publications that users recognise and abide by the legal requirements associated with these rights.

- Users may download and print one copy of any publication from the public portal for the purpose of private study or research.

- You may not further distribute the material or use it for any profit-making activity or commercial gain

- You may freely distribute the URL identifying the publication in the public portal

If you believe that this document breaches copyright please contact us providing details, and we will remove access to the work immediately and investigate your claim 


\title{
Direct evidence for positron annihilation from shallow traps
}

\author{
S. Linderoth ${ }^{*}$ and C. Hidalgo ${ }^{\dagger}$ \\ Laboratory of Applied Physics II, Technical University of Denmark, DK-2800 Lyngby, Denmark
}

(Received 11 March 1987)

\begin{abstract}
For deformed $\mathrm{Ag}$ the temperature dependence of the positron lifetime parameters is followed between 12 and $300 \mathrm{~K}$. Clear direct evidence for positron trapping and annihilation at shallow traps, with a positron binding energy of $9 \pm 2 \mathrm{meV}$ and annihilation characteristics very similar to those in the perfect lattice, are revealed. The shallow traps are annealed out below $600 \mathrm{~K}$.
\end{abstract}

Positron trapping at open-structured defects, such as vacancies and their agglomerates, is known to take place in most metals. ${ }^{1}$ Positron annihilation in a vacancy-type defect is recognized by an increased positron lifetime compared to that in the perfect lattice, ${ }^{1}$ as a result of the lower electron density sensed by the positron in the trap. The ability of the positron to respond specifically to the presence of different kinds of defects has made the positron annihilation technique a very useful tool in the studies of e.g., defect production and annealing in many materials. $^{2-4}$ Positron trapping and annihilation in shallow traps with annihilation characteristics similar to those in the perfect bulk state have been suggested. ${ }^{5-7}$ We present in this report clear, direct evidence for such shallow traps, as revealed in deformed Ag.

Positron lifetime measurements were made on $\mathrm{Ag}$ deformed at room temperature. The Ag samples $(99.99 \%$ purity) were spark cut from a rod of polycrystalline Ag. The specimens were polished, rolled, and annealed in vacuum at $1000 \mathrm{~K}$ for several hours. The samples were thereafter rolled to a thickness reduced by about $8 \%$. Positron lifetime measurements were carried out as a function of temperature from 12 to $300 \mathrm{~K}$ after annealing the $\mathrm{Ag}$ specimens in vacuum at $565 \mathrm{~K}(\mathrm{Ag} \mathrm{I}), 600 \mathrm{~K}$ ( $\mathrm{Ag} \mathrm{II})$, and $630 \mathrm{~K}$ (Ag III), respectively. For a second deformed sample set isochronal annealings were made from 320 to 630 $\mathrm{K}$ with measurements taken at room temperature.

The time measurements were performed with a standard fast-slow time spectrometer ${ }^{8}$ with a time resolution of $246 \mathrm{ps}$ [full width at half maximum (FWHM)] as found by the RESOLUTION ${ }^{9}$ program. The ${ }^{22} \mathrm{NaCl}$ source of about $100 \mu \mathrm{Ci}$, dried on a $0.45-\mathrm{mg} / \mathrm{cm}^{2} \mathrm{Ni}$ foil, was found to contribute $7.2 \%$ of the positron annihilations, with $4 \% 163-$ ps annihilations from the $\mathrm{Ni}$ foil ${ }^{10}$ and $3.2 \%$ 400-ps annihilations from the salt. This source contribution was subtracted in the analyses of the time measurements on the deformed Ag. The analyses were made by POSITRONFIT. ${ }^{9}$ The spectra were well described by two exponential decay components, the longer positron lifetime having a value of about 200 ps that remained the same within statistical uncertainties for all measurements. The results of the free analysis of the isochronal annealing measurements are presented in Fig. 1. In order to reduce the statistical scatter, the longer positron lifetime was constrained to $200 \mathrm{ps}$ for Ag I, Ag II, and Ag III. These results are shown in Figs. 2-4. The reversibility of the temperature-dependent measurements was verified.
The positron lifetime of about 200 ps is close to the lifetime found for annihilation in vacancies in $\mathrm{Ag} .{ }^{11,12}$ The existence of three-dimensional vacancy clusters formed by the deformation can therefore be ruled out. ${ }^{1}$ For many metals it has been found that the positron lifetime associated with dislocations is very close to that related to monovacancies; ${ }^{2}$ hence we conclude that the positron-trapping component originates from trapping at dislocations. The recovery stage at around $550 \mathrm{~K}$ (cf. Fig. 1) is assigned to the annealing of dislocations produced by the deformation.

The main features of the temperature dependence of the positron lifetime parameters are a strong increase of the intensity $I_{2}$ with increasing temperature for the specimen when annealed at $565 \mathrm{~K}$ (Ag I), while annealing at $600 \mathrm{~K}$ (Ag II) makes this temperature dependence almost

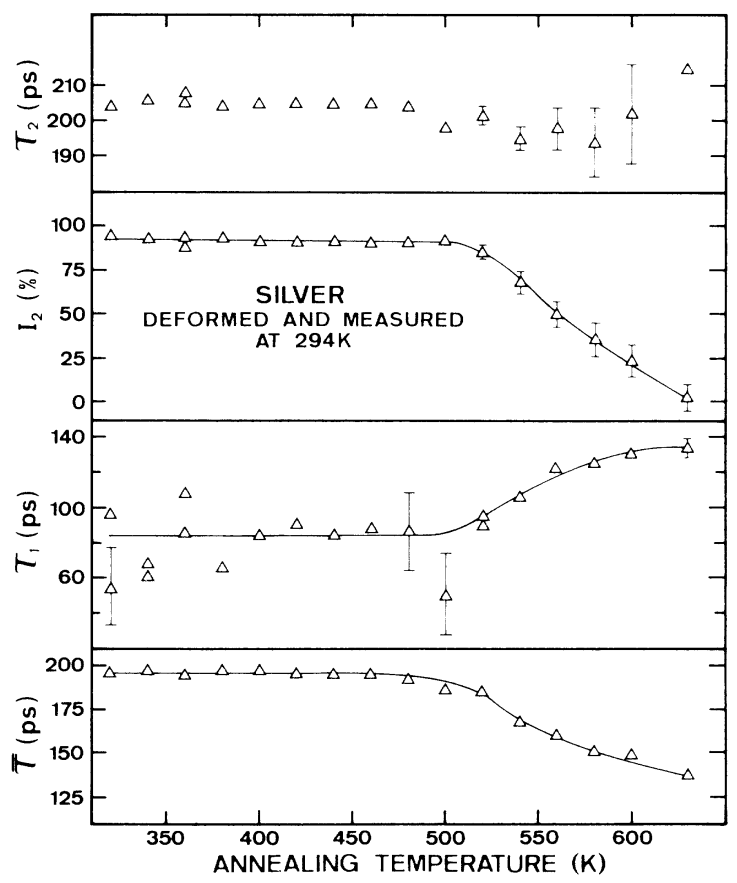

FIG. 1. Positron lifetime parameters vs annealing temperature in $\mathrm{Ag}$ deformed at room temperature. Isochronal annealing rate: $30 \mathrm{~K} / \mathrm{h}$. 


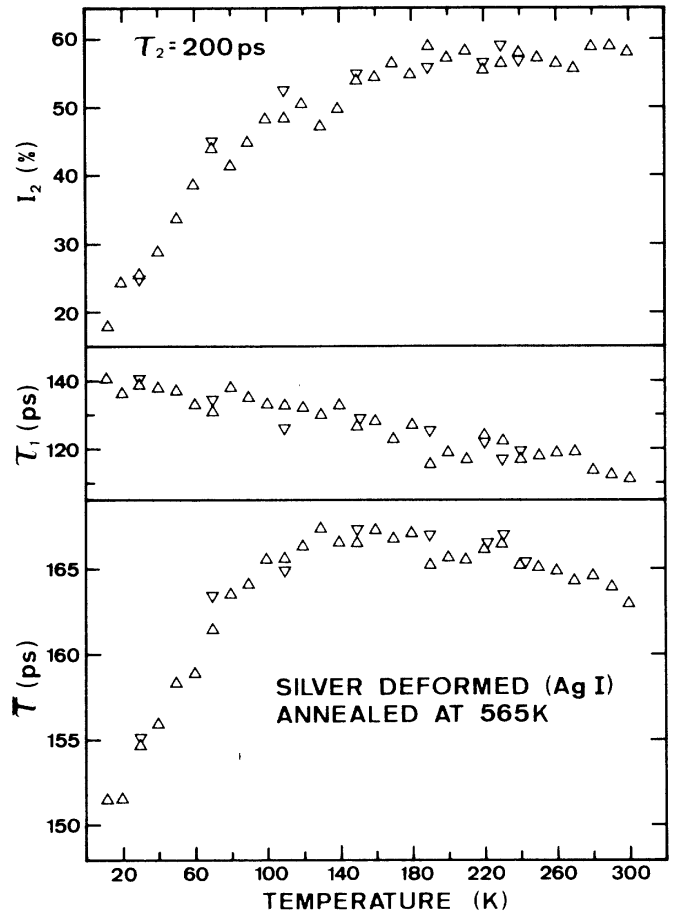

FIG. 2. Positron lifetime parameters as a function of temperature in deformed $\mathrm{Ag}$ annealed at $565 \mathrm{~K}$.

vanish. This is also clearly reflected in the mean positron lifetime deduced from $\bar{\tau}=\tau_{1} I_{1}+\tau_{2} I_{2}$. For Ag I the shortest lifetime $\tau_{1}$ remains at a value of about $136 \mathrm{ps}$ below $100 \mathrm{~K}$, although $I_{2}$ changes significantly from $18 \%$ to about $50 \%$ at the lowest temperatures. The value of 136 ps is close to the bulk lifetime $\left(\tau_{b}=133 \pm 2\right.$ ps $)$ observed at room temperature in completely recovered Ag. This is taken as clear evidence for shallow positron traps in Ag with annihilation characteristics very similar to those in the perfect lattice. At the lowest temperatures, the trapping probability becomes sufficiently high that most positrons are in a trap, shallow or deep, upon annihilation. At

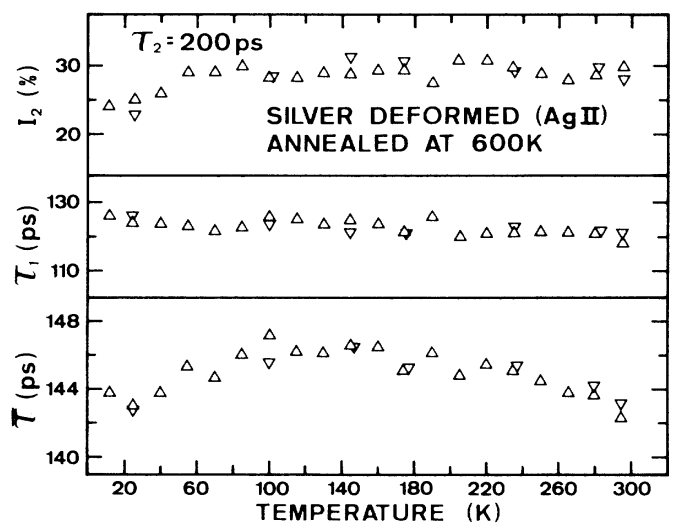

FIG. 3. Positron lifetime parameters vs temperature in deformed $\mathrm{Ag}$ annealed at $600 \mathrm{~K}$.

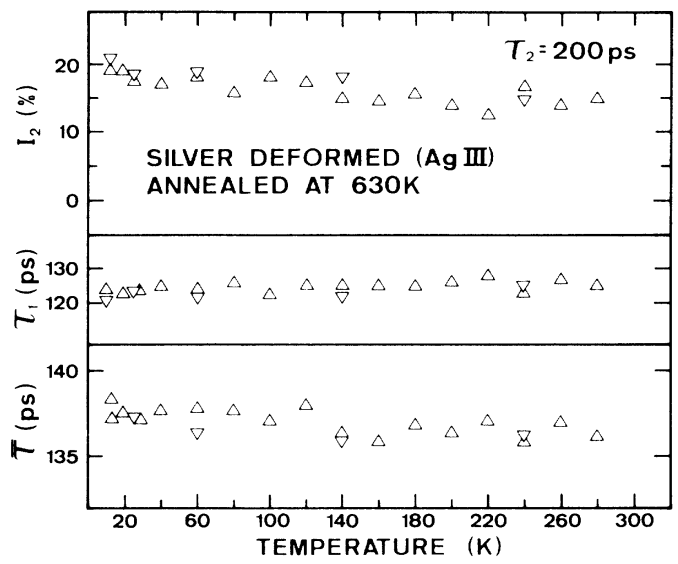

FIG. 4. Positron lifetime parameters vs temperature for deformed $\mathrm{Ag}$ annealed at $630 \mathrm{~K}$.

elevated temperatures the shallow traps are depleted and the deeper trap becomes the dominant annihilation site. Annealing at a temperature only $35 \mathrm{~K}$ higher removes most of the shallow traps (cf. Fig. 3) and, after annealing at $630 \mathrm{~K}$ (cf. Fig. 4), only the deeper trap is observed to be present. The trapping model ${ }^{13}$ incorporating only a single trap state is now satisfied. It is important to note that, after removing the shallow traps, the trapping to the deep trap is basically temperature independent in the studied temperature range, which means that the temperature dependence of $I_{2}$ found for $\mathrm{Ag} \mathrm{I}$ is entirely due to the presence of shallow traps.

From a three-state trapping model ${ }^{13}$ that includes trapping to a deep and a shallow-type defect as well as detrapping from the shallow trap back into the bulk, the positron binding energy $\left(E_{b}\right)$ to the shallow trap can be estimated. As the longer-lived component, which originates from annihilation from the deep trap is well separated from the two shorter-lived components, incorporated in one lifetime component, it follows that

$$
I_{2}=\frac{K_{d}\left(\lambda_{d}-\lambda_{s}-\varepsilon\right)}{\left(\lambda_{d}-\lambda_{s}\right)\left(\lambda_{f}+K_{s}+K_{d}-\lambda_{d}\right)-\left(\lambda_{f}+K_{d}-\lambda_{d}\right) \epsilon},
$$

where $\left(\lambda_{s}, K_{s}\right)$ and $\left(\lambda_{d}, K_{d}\right)$ are the annihilation and trapping rates to the shallow and deep traps, respectively. $\lambda_{f}$ is the annihilation rate in the perfect lattice and $\varepsilon \propto \exp \left(-E_{b} / k_{B} T\right)$ is the detrapping rate from the shallow trap. Equation (1) may also be written as

$$
\Delta\left(1 / I_{2}\right)=1 / I_{2}-1 / I_{2}^{0}=\frac{K_{s}}{K_{d}}\left(\frac{\lambda_{s}-\lambda_{d}}{\lambda_{s}-\lambda_{d}+\varepsilon}\right),
$$

where $I_{2}^{0}$ is the intensity of the longer-lived component when detrapping processes are very active, e.g., for $T>100 \mathrm{~K}$. It then follows that $\ln \Delta\left(1 / I_{2}\right) \propto E_{b} / k_{B} T$ when $\varepsilon \gg \lambda_{s}-\lambda_{d}$, while $\ln \Delta\left(1 / I_{2}\right)=\ln \left(K_{s} / K_{d}\right)$ for $\varepsilon \ll \lambda_{s}-\lambda_{d}$. The strong temperature dependence of $\ln \Delta\left(1 / I_{2}\right)$, shown in Fig. 5 is due to detrapping from the shallow trap. From the Arrhenius plot the positron binding energy to the trap can be estimated to be $9 \pm 2 \mathrm{meV}$. Below $30 \mathrm{~K}$ detrapping 


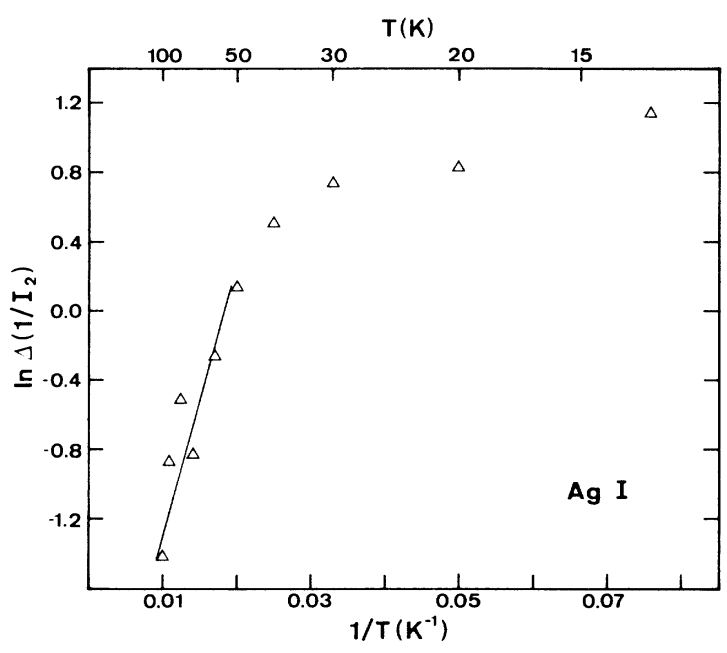

FIG. 5. Arrhenius plot of $\Delta\left(1 / I_{2}\right)$ for Ag I.

becomes less efficient, and hence $\ln \Delta\left(1 / I_{2}\right)$ tends toward a constant value from which $K_{s} \gtrsim K_{d}$ can be obtained. This result is consistent with the above interpretation, where it is implicit that the trapping rate to the shallow trap is sufficiently large to trap a considerable fraction of the positrons at low temperatures.

Shallow traps have often been suggested to be the cause of different temperature dependences of positron annihilation parameters, although no clear experimental confirmation of such traps has been presented. The increased fraction of positrons annihilating in voids in Mo, ${ }^{6}$ when increasing the temperature, has been attributed to detrapping of positrons from shallow traps, and some indications for positron annihilation in shallow traps have also been presented. ${ }^{6}$ The intrinsic trapping rate to the voids, however, is also found to increase with temperature. ${ }^{14-16} \mathrm{Re}$ sults on neutron-irradiated $\mathrm{Al}$, studied with variableenergy positrons, have been interpreted as evidence for annihilation from shallow traps. ${ }^{17}$ However, positron lifetime spectroscopy on similarly manufactured samples showed that the annihilation occurred mainly from voids and vacancylike defects, presumably jogs at dislocation loops. ${ }^{15}$ The dislocation line is thought to be a shallow trap that acts as a precursor state for trapping to the jog, ${ }^{18}$ and it is the temperature dependences of the specific trapping and detrapping rates to and from the line that is reflected in the increased trapping to jogs when lowering the temperature. ${ }^{19}$

The present measurements on deformed $\mathrm{Ag}$ reveal an atypical behavior where the fraction of positrons annihilating in the longest-lived component is lowered with decreasing temperature, reflecting the competing trapping between the deep and the shallow traps. Dopplerbroadening measurements on deformed $\mathrm{Cu}$ (Ref. 20) may be understood in a very similar fashion. ${ }^{5}$ The more informative lifetime measurements settle this and, simultaneously, reveal that the positron annihilation rate in the shallow trap is similar to that in the perfect bulk state. Grain boundaries may act as shallow traps, ${ }^{5}$ but the grain sizes in our specimens are expected to be too large to produce significant trapping.

It should be noticed that the shallow traps anneal out before the complete annealing of the deep traps, which are identified as jogged dislocations.

It is possible that dislocation lines with a low density of jogs may act as the shallow trap. It has also been pointed out that low-atomic-density regions surround interstitial clusters, which may serve as shallow trap sites with bulklike characteristics. ${ }^{7}$ An impurity-defect center (e.g., a vacancy-impurity complex) is also a possible candidate as a shallow trap.

In conclusion, we have presented direct evidence for positron annihilation from shallow traps with annihilation characteristics close to those in the perfect lattice. The positron binding energy to the shallow trap has been deduced to be $9 \pm 2 \mathrm{meV}$. Interstitial clusters, impuritydefect centers, and dislocation lines are candidates as the shallow trap whereas jogged dislocations serve as the deep trap.

We thank I. K. MacKenzie for comments and a critical reading of the manuscript.
${ }^{*}$ Present address: Physics Laboratory, H. C. $\emptyset$ rsted Institute, University of Copenhagen, Universitetsparken 5, DK-2100 Copenhagen, Denmark.

†Present address: Departemento de Fisica del Estado Solido, Facultad de Ciencias Fisicas, Universidad Complutense, 28040 Madrid, Spain.

${ }^{1}$ R. M. Nieminen and M. J. Manninen, in Positrons in Solids, edited by P. Hautojärvi (Springer-Verlag, Berlin, 1979), p. 145.

${ }^{2} \mathrm{~K}$. Petersen, in Positron Solid-State Physics, edited by W. Brandt and A. Dupasquier (North-Holland, Amsterdam, 1983), p. 298.

${ }^{3}$ M. Eldrup, in Ref. 2, p. 644.

${ }^{4}$ A. Dupasquier, in Ref. 1, p. 197.

${ }^{5}$ I. K. MacKenzie, Phys. Rev. B 16, 4705 (1977).

${ }^{6}$ P. J. Schultz, K. G. Lynn, I. K. MacKenzie, Y. C. Jean, and
C. L. Snead, Phys. Rev. Lett. 44, 1629 (1980).

${ }^{7}$ R. M. Nieminen, in Ref. 2, p. 359.

${ }^{8}$ P. Hautojärvi and A. Vehanen, in Ref. 1, p. 1.

${ }^{9}$ P. Kirkegaard, M. Eldrup, O. E. Mogensen, and N. J. Pedersen, Comput. Phys. Commun. 23, 307 (1981).

${ }^{10}$ S. Linderoth, H. E. Hansen, B. Nielsen, and K. Petersen, Appl. Phys. A 33, 25 (1984).

${ }^{11}$ P. Hautojärvi, J. Johansson, A. Vehanen, J. Yli-Kauppila, P. Girard, and C. Minier, J. Phys. F 11, 1337 (1981).

${ }^{12}$ W. Lühr-Tanck, T. Kurschat, and T. Hehenkamp, Phys. Rev. B 31, 6994 (1985).

${ }^{13}$ A. Seeger, Appl. Phys. 4, 183 (1974).

${ }^{14}$ M. D. Bentzon, S. Linderoth, and K. Petersen, in Positron Annihilation, edited by P. C. Jain, R. M. Singru, and K. P. Gopinathan (World Scientific, Singapore, 1985), p. 485.

${ }^{15}$ S. Linderoth, M. D. Bentzon, H. E. Hansen, and K. Petersen, 
in Ref. 14, p. 494.

${ }^{16}$ R. M. Nieminen, J. Laakkonen, P. Hautojärvi, and A. Vehanen, Phys. Rev. B 19, 1397 (1979).

${ }^{17}$ P. J. Schultz, K. G. Lynn, R. N. West, C. L. Snead, and I. K. MacKenzie, Phys. Rev. B 25, 3627 (1982).

${ }^{18}$ M. Doyama and R. M. J. Cotterill, in Positron Annihilation, edited by R. R. Hasiguti and K. Fujiwara (Japan Institute of Metals, Sendai, 1979), p. 89.

${ }^{19}$ L. C. Smedskjaer, M. Manninen, and M. Fluss, J. Phys. F 10, 2237 (1980).

${ }^{20}$ P. Rice-Evans, T. Hlaing, and I. Chaglar, Phys. Rev. Lett. 37, 1415 (1976). 